\title{
Determination of deformations and self-stress in concrete on stress cement
}

\author{
Saidkhan Salikhanov", Zulfiya Pulatova, Fahriddin Zakirov, Ziyavuddin Rahimjonov, and \\ Abdurahim Abdullayev
}

Tashkent State Transport University, Tashkent, Uzbekistan

\begin{abstract}
The article considers using a single-layer reinforced tencentimeter layer of concrete on stress cement instead of the traditional multilayer construction of waterproofing bridges. The proposed design will ensure the water tightness of the bridge deck due to the self-stress in the concrete on the stressing cement, the value of which is proportional to the deformations of concrete and reinforcement. Concrete deformations are uneven over the layer height, and the resulting stress in concrete depends on the reinforcement coefficient. Experiments were carried out to determine the deformations of concrete and the magnitude of self-stress, which provides the waterproofing properties of a bridge deck made of concrete on stress cement. The study of the self-tension process, identifying those factors on which its value depends, is necessary for a correct understanding of the physics of the self-tension process. In addition, it is necessary to check the applicability of various proposed empirical dependences for concrete on stress cement of the composition under consideration.
\end{abstract}

\section{Introduction}

The main function of the traditional construction of the bridge deck, consisting of leveling, waterproofing, and protective layers, is to protect the main load-bearing elements of the superstructure. At the same time, the dead weight of this "pie" is a forced constant load, which acts on the main beams of the superstructure and requires additional consumption of reinforcement to absorb the forces arising from this load.

The rational design of the bridge deck could be achieved by installing one tencentimeter layer of self-stressed concrete, which serves as leveling, waterproofing, and protective layers.

In works [1, 2] and [3], the construction of a bridge deck was considered, consisting of a ten-centimeter layer, reinforced with a mesh of ten-millimeter rods along the entire length and width of the bridge. The reinforcement ratio in both directions is $0.4 \%$. Compared to the traditional construction of the bridge deck, tangible savings in metal were achieved (within 12-15\%), mainly due to a decrease in the number of working reinforcement, taking into account the joint work of the main beams with the layer of the bridge deck.

\footnotetext{
* Corresponding author: zulya1787@gmail.com
} 


\subsection{The purpose of the construction of a concrete layer on the stress cement of the bridge deck}

The purpose of the new construction of the bridge deck, consisting of one layer of selfstressed concrete and replacing three traditional layers, is water tightness. Following the "Instruction for the design of self-stressed reinforced concrete structures SN 511-78" [4], the water tightness of a concrete slab on stress cement will be ensured at a self-stress value (taking into account losses from shrinkage and creep) of at least $0.5 \mathrm{MPa}$.

As is known [5-8], self-stress of concrete on NC, which occurs when its free expansion is limited, does not obey the laws of elastic bodies. Determination of the magnitude of selfstress, which ensures the waterproofing properties of a bridge deck made of concrete on stress cement, the study of the process of its occurrence, the identification of those factors on which its value depends, is necessary for a correct understanding of the physics of the self-stress process. In addition, it is essential to check the applicability of various proposed empirical relationships for concrete on stress cement of the composition under consideration.

\section{Methods and Materials}

\subsection{Deformations of concrete on stress cement}

In the presence of reinforcement, a bound deformation of the concrete arises on the stress cement, which is the difference between the deformations of free expansion and limited deformation

$$
\varepsilon_{\text {ass }}=\varepsilon_{f r}-\varepsilon_{\text {lim }}
$$

By limited expansion $\varepsilon_{\text {lim }}$ we mean the deformation of concrete on stress cement, which is not allowed due to the presence of limiting conditions. In turn, limited deformation consists of plastic (seal deformation) and elastic parts, i.e.:

$$
\varepsilon_{l i m}=\varepsilon_{e l}+\varepsilon_{p l}
$$

Elastic deformation $\mathcal{E}_{e l}$ is understood as the reversible part of the limited deformation. Under the plastic deformation $\mathcal{E}_{p l}$ is understood the irreversible part of the limited deformation.

Hence the deformation of free expansion:

$$
\varepsilon_{f r}=\varepsilon_{a s s}+\varepsilon_{p l}+\varepsilon_{e l}
$$

It is obvious that

$$
\varepsilon_{e l}=\frac{\sigma_{s} A_{s}}{E_{b} A_{b}}
$$

Here $\sigma_{\mathrm{s}}$ is the stress in the reinforcement limiting free expansion (with reinforcement in one direction); $A_{s}$ is the area of reinforcement, $A_{b}$ is the concrete area; $E_{b}$ is the modulus of elasticity of concrete on the PC.

We can write: 


$$
\varepsilon_{f r}-\varepsilon_{p l}-\frac{\sigma_{s} A_{s}}{E_{b} A_{b}}=\frac{\sigma_{s}}{E_{s}}
$$

Here $\sigma_{s} E_{s}^{-1}$ is deformation of reinforcement, which is equal to the associated expansion of concrete on stress cement due to compliance with the compatibility conditions for deformations of concrete and reinforcement.

\subsection{Determination of stresses in concrete on stress cement}

The self-stress in concrete is determined by the formula:

$$
\sigma_{b}=\left(\varepsilon_{f r}-\varepsilon_{p l}-\frac{\sigma_{s}}{\mathrm{E}_{s}}\right) \mathrm{E}_{b}
$$

Determination of the experimentally reversible part of the limited deformation, i.e. $\varepsilon_{e l}$ makes it possible to determine the modulus of elasticity of concrete on stress cement with bound deformation:

$$
\mathrm{E}_{b}=\left(\frac{\sigma_{s} A_{s}}{A_{b} \varepsilon_{e l}}\right)
$$

The magnitude of self-stress for different reinforcement can be calculated in two ways:

$$
\sigma_{b}=\mathrm{E}_{b} \varepsilon_{e l} \text { and } \sigma_{b}=\mathrm{E}_{b}^{\prime} \varepsilon_{e l}
$$

Here $\mathrm{E}_{\mathrm{b}}$ is tangent modulus of elasticity of concrete at stress cement;

$\mathrm{E}_{\mathrm{b}}^{\prime}$ is secant modulus of elasticity of concrete on stress cement (Figure 1);

$\varepsilon_{e l}$ is reversible part of limited deformation;

$\varepsilon_{\text {lim }}$ is total limited deformation.

\subsection{Experimental studies to determine deformations and stresses}

To carry out tests to determine the values of free, bound, reversible, and irreversible parts of limited expansion, 12 prisms with dimensions of $10 \times 10 \times 40 \mathrm{~cm}$ and six cubes with dimensions of $15 \times 15 \times 15 \mathrm{~cm}$ were made from the concrete of the composition mentioned above. The manufacturing technology of the samples and the process of their expansion were as follows.

The slump of the concrete cone was $5 \mathrm{~cm}$. The prisms were concreted in conventional metal molds. The embedded parts for the installation of measuring instruments were prefixed. The concrete was compacted on a platform vibrating table. After manufacturing, the samples were covered with a polyethylene film to protect them from intense evaporation of moisture during the hardening period and the appearance of shrinkage cracks. When concrete acquired strength on average $\mathrm{R}_{\mathrm{av}}=10 \mathrm{MPa}$ (after two days, it was determined by testing three free cubes), the samples were decomposed and installed in special conductors (Fig.2). The design of the conductor differed from the one recommended in [9] and [10] by the significant rigidity of the traverse, which makes it possible to consider the traverse as non-deformable. Each traverse consists of two channels No. 10 (1), welded to each other. Between the walls of the channels of each traverse, two tubes (2) with an inner diameter of $16 \mathrm{~mm}$ with a wall thickness of $5 \mathrm{~mm}$ are installed, welded to the walls of the channels. Through the tubes, the connecting traverses (3) of reinforcing steel, fixed with nuts and locknuts, pass. By changing the diameter of the rods, a change in the reinforcement coefficient (degree of restriction) was achieved. 


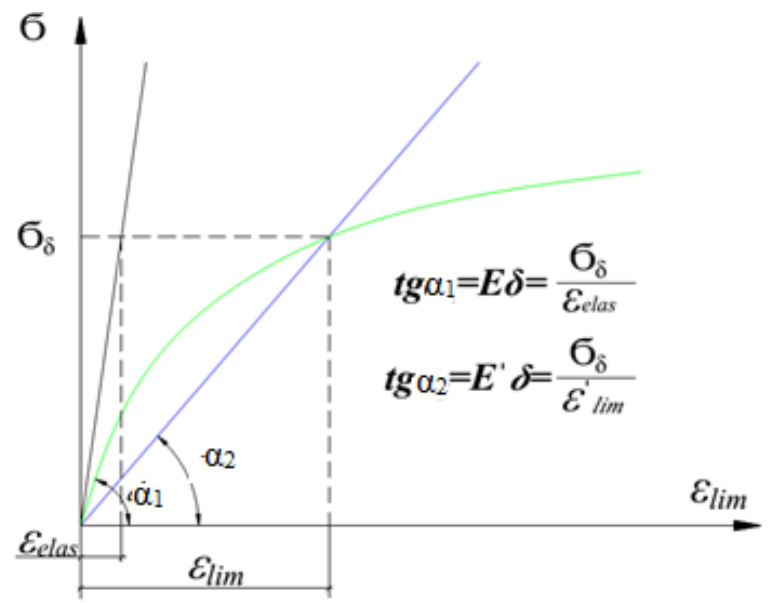

Fig. 1. To the determination of the magnitude of self-voltage in concrete on stress cement

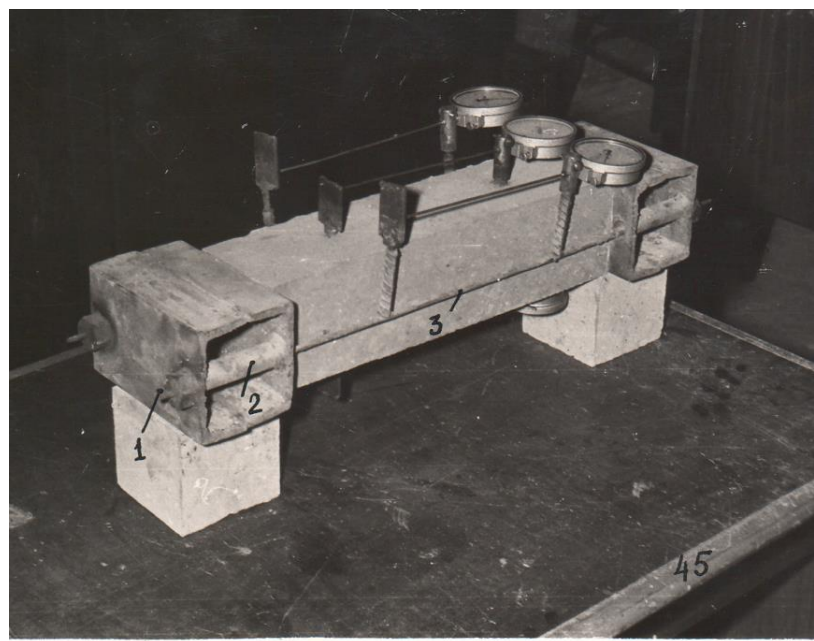

Fig.2. General view of the sample in the jig

Three series of prisms, three in each, were installed in conductors with reinforcement, respectively, $\mu=0.004 ; \mu=0.010 ; \mu=0.016$, which corresponds to the rods diameters $d=$ $5 \mathrm{~mm} ; \mathrm{d}=8 \mathrm{~mm} ; \mathrm{d}=10 \mathrm{~mm}$. Then all samples were completely submerged in water. The value of free expansion was determined in three prisms. The associated expansion of concrete and deformation of reinforcement in reinforced prisms was measured based on $200 \mathrm{~mm}$ with indicators of type 1 IGM with the graduation of $0.001 \mathrm{~mm}$. The process of expansion of concrete on stress-cement reinforced and unreinforced prisms in time is shown in Fig. 3.

Stabilization of deformations of free and bound extensions occurred on the 13th day of watering. In this case, the average values of the relative bound deformation of concrete, depending on the coefficient of reinforcement, were: at $\mu=0.004, \varepsilon_{a s s}=0.00134$, at $\mu=$ $0.010, \varepsilon_{\text {ass }}=0.00081$, at $\mu=0.016, \varepsilon_{\text {ass }}=0,00052$.

In this case, the experimentally determined values of the deformations of the samples had the following values of the root-mean-square deviation $\sigma$, the coefficient of variation $\mathrm{v}$, the confidence interval of the error $\mathrm{m}$, and the accuracy index $\beta$ : 


$$
\begin{array}{llllrl}
\text { at } \mu=0.004 & \sigma=5.0 \cdot 10^{-5} ; & v= \pm 3.73 \% ; & m \pm 8.67 ; & \beta=2.15 \% \\
\text { at } \mu=0.01 & \boldsymbol{\sigma}=8.1 \cdot 10^{-5} ; & v= \pm 9.9 \% ; & m= \pm 14.04 ; & \beta=5.7 \% ; \\
\text { at } \mu=0.016 & \boldsymbol{\sigma}=6.6 \cdot 10^{-5} ; & v \pm 12 \% ; & m= \pm 11.44 ; & \beta=7 \% .
\end{array}
$$

The deformation of the reinforcement was, respectively, $\varepsilon_{f r}=0.00131 ; \varepsilon_{f r}=0.00078$; $\varepsilon_{f r}=0.0005$. In unreinforced prisms, the free expansion was $\varepsilon_{f r}=0.00415$. The value of the root-mean-square deviation from the mean was $\sigma=2.758$. In this case, the values of the relative limited deformation: at $\mu=0.004 \varepsilon_{\text {lim }}=0.00224$; at $\mu=0.010 \varepsilon_{\text {lim }}=0.00337$; at $\mu$ $=0.016 \varepsilon_{\text {lim }}=0.00365$ (table 1$)$.

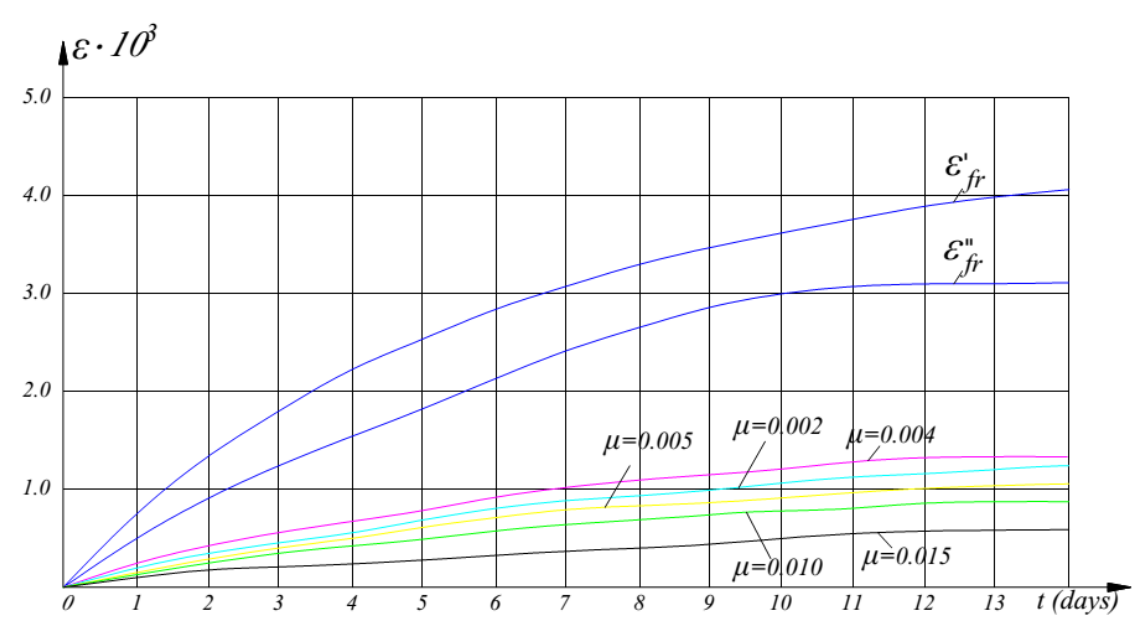

Fig.3. Expansion process of reinforced and unreinforced concrete prisms on stress cement over time

Then, all the samples were taken out of the water and put into air storage under room conditions for 2 days. After that, the reinforcement was released by synchronous unscrewing of the nuts, and the elastic (reversible) part of the limited deformation was observed using the indicators installed on the concrete. To check whether the reversibility of the deformation continues in time after the tempering of the reinforcement, the readings of the indicators were observed for 2 days. It was found that after three hours, the values of reversible deformations increased significantly (on average by $50 \%$ ). For the elastic deformation of self-stressed concrete in a bound state, the complete reversible deformation, determined two days after unloading, is taken. In fact, this is the sum of elastic and viscous deformations. Since the viscous deformation actually grew very quickly (over three hours), this approach can be considered legitimate and, as it were, equivalent to the replacement of the reversible part of the creep deformation with a vertical segment, which is accepted in the modified theory of aging, that is, instantaneously, venous elastic [12-14].

On the second day, the instruments began to show concrete compression, i.e., shrinkage deformation began to exceed expansion. The average values of the total reversible deformations with the reinforcement coefficients $\mu=0.004, \mu=0.01, \mu=0.016$, respectively, were: $\varepsilon_{e l}=0.00005, \varepsilon_{e l}=0.00006 . \varepsilon_{e l}=0.00006$. In this case, the standard deviation from the average for all series was $\sigma=1.2$. The accuracy index did not exceed $7 \%$, the coefficient of variation was $10 \%$.

Then the values of plastic deformations (seal deformations) were determined by the formula: 


$$
\varepsilon_{p l}=\varepsilon_{f r}-\varepsilon_{a s s}-\varepsilon_{e l}
$$

Table 1

\begin{tabular}{|c|c|c|c|c|c|c|c|c|c|c|}
\hline № & $\mu$ & $\varepsilon_{f r}$ & $\varepsilon_{\text {ass }}$ & $\varepsilon_{\text {lim }}$ & $\varepsilon_{e l}$ & $\varepsilon_{p l}$ & $K_{a s s}$ & $K_{\text {lim }}$ & $K_{e l}$ & $K_{p l}$ \\
\hline 1 & 0 & $\frac{.00314^{*}}{0.00415}$ & & 0 & 0 & 0 & 0 & 0 & 0 & 0 \\
& & & & & & & & & \\
\hline 2 & 0.00 & 0.00314 & 0.00 & 0.001 & 0.000 & 0.001 & 0.424 & 0.576 & 0.009 & 0.570 \\
& 2 & & 133 & 81 & 03 & 79 & & & 5 & \\
\hline 3 & 0.00 & 0.00415 & 0.00 & 0.002 & 0.000 & 0.002 & 0.322 & 0.677 & 0.012 & 0.665 \\
& 4 & & 134 & 81 & 05 & 76 & & & 0 & \\
\hline 4 & 0.00 & 0.00314 & 0.00 & 0.002 & 0.000 & 0.002 & 0.318 & 0.681 & 0.012 & 0.668 \\
& 5 & & 1 & 14 & 04 & 10 & & & 7 & \\
\hline 5 & 0.01 & 0.00415 & 0.00 & 0.003 & 0.000 & 0.003 & 0.195 & 0.805 & 0.014 & 0.790 \\
& 0 & & 081 & 34 & 06 & 28 & & & 4 & \\
\hline 6 & 0.01 & 0.00415 & 0.00 & 0.003 & 0.000 & 0.003 & 0.125 & 0.875 & 0.014 & 0.860 \\
& 6 & & 052 & 63 & 06 & 57 & & & 4 & \\
\hline
\end{tabular}

* - the numerator gives the value of free expansion of concrete on stress cement with $\mu$ $=0.002$ and $\mu=0.005$; in the denominator - with $\mu=0.004 ; \mu=0.01$; and $\mu=0.016$.

Since the deformation of free expansion with the same composition of the stressing concrete is quite stable, it is possible to evaluate the characteristics of the constituent deformations by its value using the following relations:

$$
K_{a s s}=\frac{\varepsilon a s s}{\varepsilon_{f r}} ; K_{l i m}=\frac{\varepsilon_{l i m}}{\varepsilon_{f r}} ; K_{e l}=\frac{\varepsilon_{e l}}{\varepsilon_{f r}} ; K_{p l}=\frac{\varepsilon_{p l}}{\varepsilon_{f r}} ;
$$

In addition to tests to determine the coupled expansion and the elastic part of limited expansion on prisms enclosed in conductors, two more series (three prisms in each) of prisms were tested, reinforced with rods centrally located in the concrete body, insulated with a polyethylene film.

In one series, the diameter of the rod is $5 \mathrm{~mm}(\mu=0.002)$; in the other series, $8 \mathrm{~mm}(\mu=$ $0.005)$. These prisms were made from a different batch. Free expansion was $\varepsilon_{f r}=0.00314$. The process of expanding concrete on tensile cement of reinforced and unreinforced prisms in time is shown in Fig. 3.

Data for all five series are shown in Table 2.

The $\mathrm{K}_{\mathrm{ass}}$ coefficient, depending on the reinforcement coefficient, is approximated by the curve

$$
K_{\text {ass }}=1-2.02 \mu^{0.2}
$$

When approximating, taking into account the fact that at $\mu=0, \mathrm{~K}_{\mathrm{ass}}=0$, six experimental values were processed (Fig.4).

Experimental values of self-stress of concrete were determined from the experimental values of deformation in reinforcing bars (rods):

$$
\sigma_{b}=\left(\frac{\sigma_{s} A_{s}}{A_{b}}\right)
$$

where

$$
\sigma_{s}=\varepsilon_{s} E_{s}
$$




\section{Results and Discussion}

\subsection{The relationship between the magnitude of self-stress, the coefficient of reinforcement, and free expansion}

As a result of statistical processing, a relationship was obtained between the value of selfstress, the coefficient of reinforcement, and free expansion:

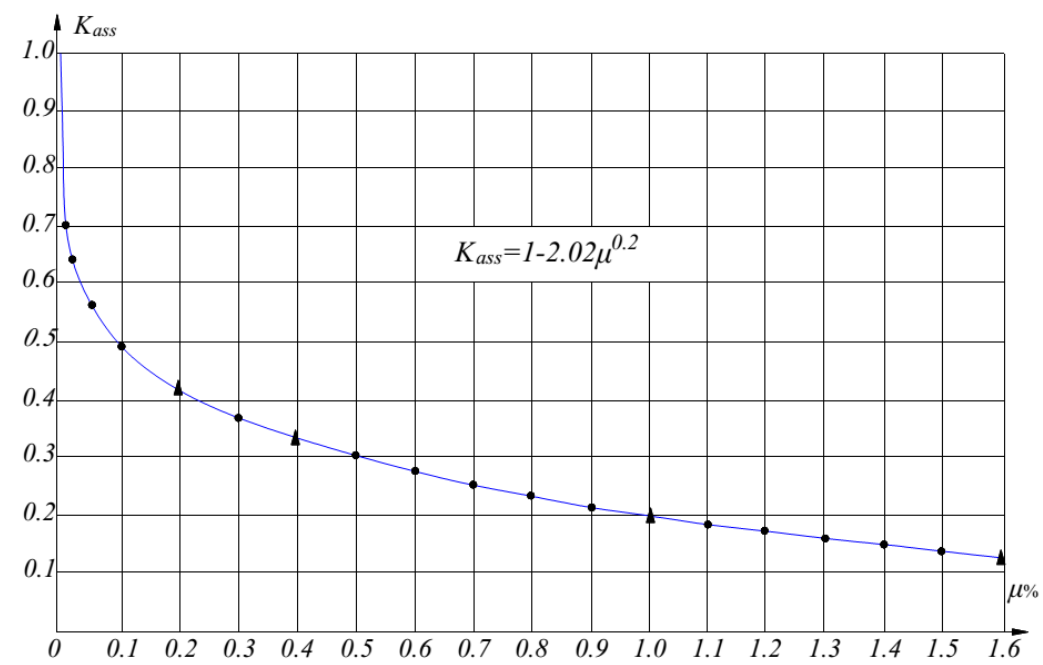

Fig. 4. Associated expansion versus uniaxial reinforcement ratio. $\mathbf{\Delta}$ are experienced points.

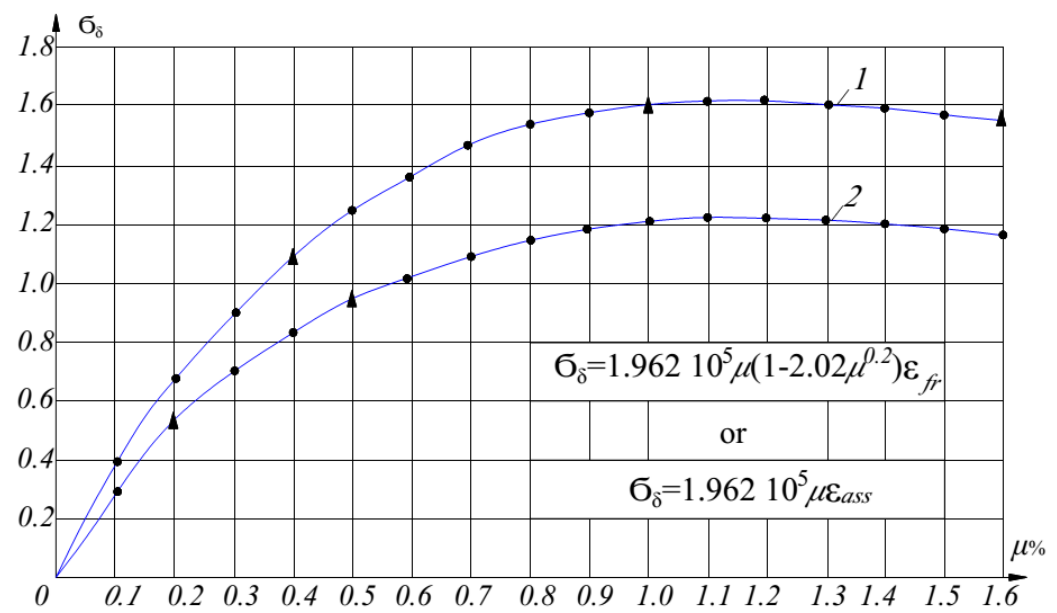

Fig.5. Dependence of the value of self-stress on the coefficient of uniaxial reinforcement (1-at

$$
\begin{aligned}
& \left.\varepsilon_{f r}=0.00415 ; 2 \text {-at } \varepsilon_{f r}=0.00314\right) . \Delta \text { are experienced points. } \\
\sigma_{b}= & 1.962 \cdot 10^{5} \mu\left(1-2.02 \mu^{0.2}\right) \varepsilon_{f r}
\end{aligned}
$$

The relationship between the magnitude of the self-stress, the coefficient of reinforcement, and the associated expansion is as follows:

$$
\sigma_{b}=1.962 \cdot 10^{5} \mu \varepsilon_{a s s}
$$


The graphs constructed according to the dependencies (13) and (14) are shown in Fig.5.

\section{Conclusions}

It seems that the most convenient for practical use is the formula (13), according to which the magnitude of the self-stress depends directly on the magnitude of the free expansion. The transition from formula (13) to (14) is easily done using the graph shown in Figure 4.

Let us compare the experimental values of self-stress with their values obtained by various proposed formulas. Experienced self-stress values are determined by the formula:

$$
\sigma_{b}=\frac{\sigma_{s} A_{s}}{A_{b}}=\sigma_{s} \mu
$$

Here is the stress in the reinforcing rods calculated from the measured values of the associated deformations.

Table 2 (column 3) shows the experimental self-stress values. Column 4 of the table shows the self-voltage values calculated by the formula proposed [15-19].

$$
\sigma_{b}=0.085\left(\sigma_{b}^{I}\right)^{1.25}\left(\frac{1}{\varepsilon_{a s s}}\right)^{0,25}
$$

Here $\sigma 1 \mathrm{~b}$ is the energy grade of concrete on stress cement in $\mathrm{kgf} / \mathrm{cm} 2$ at $\mu=1 \%$.

The values of $\varepsilon_{\text {ass }}$, not obtained experimentally, were calculated using the dependence

$$
\varepsilon_{\text {ass }}=\left(1-2.02 \mu^{0,2}\right) \varepsilon_{f r}
$$

Column 6 of Table 2 shows the values of self-stress according to the formula recommended by the "Instruction for the design of self-stressed reinforced concrete structures, SN 511-78" [4].

The magnitude of self-stress is determined depending on the design grade of concrete on self-stressing cement for self-stress, the coefficient of reinforcement, as well as the location of the reinforcement in the section:

$$
\begin{gathered}
\sigma_{b}=R\left(\frac{1}{\varepsilon_{a s s}}\right)^{0,25} \\
\sigma_{b}=R_{s s} K_{\mu} K_{a} K_{e}
\end{gathered}
$$

Here $R_{s s}$ is determined depending on the design grade of concrete on stressing cement by self-stress according to table 2 .

Table 2

\begin{tabular}{|c|c|c|c|c|c|c|c|c|}
\hline \multicolumn{8}{|c|}{ Self-tension of concrete $R_{s s}, \mathrm{~kg} / \mathrm{cm}^{2}$ at design grade } \\
\hline${ }^{*}$ St 6 & St 8 & St 10 & St 12 & St 15 & St 20 & St 25 & St 30 & St 40 \\
\hline 4.8 & 6.4 & 8 & 9.6 & 12 & 16 & 20 & 24 & 32 \\
\hline
\end{tabular}

"St - self-tension

The self-stressing grade of concrete is the self-stress value determined on control prism specimens with a size of 10x10x40 cm, molded and hardened under normal wet conditions in a dynamometric jig, which creates an elastic deformation limitation during the expansion of the specimen concrete, which is equivalent to longitudinal reinforcement in the amount of $1 \%$.

K $\mu$ - coefficient depending on the total reinforcement coefficient $\mu \Pi=\mu+\mu$, determined by the formula 


$$
K_{\mu}=\sqrt{\frac{1,57 \mu_{\mathrm{m}}}{0,0057+\mu_{\mathrm{n}}}}
$$

$K_{a}$ is a coefficient depending on the nature of the reinforcement; with uniaxial reinforcement $\mathrm{Ka}=1.0$; with biaxial $K_{a}=1.2$; with a triaxial $K_{a}=1.5$.

$K_{e}$ is coefficient depending on the location of the reinforcement relative to the center of the section

$$
K_{\mathrm{e}}=1-\frac{\mathrm{e}}{h_{0}-a^{\prime}}
$$

Here $e$ is the distance from the center of gravity of the concrete section to the center of all longitudinal reinforcement.

In our case: $\overline{R_{s t}}=15.6 \mathrm{kgf} / \mathrm{cm}^{2}$; according to table $2.2 . \mathrm{R}_{\mathrm{st}}=12.48 \mathrm{kgf} / \mathrm{cm}^{2}$; at $\mu=$ $0.002 \mathrm{~K} \mu=0.64$; at $\mu=0.004 \mathrm{~K} \mu=0.80$; at $\mu=0.005 \mathrm{~K} \mu=0.86$; at $\mu=0.010 \mathrm{~K} \mu=1.0$; at $\mu=0.016 \mathrm{~K} \mu=1.72 ; \mathrm{Ke}=1.0$.

Column 8 of Table 2 contains the self-stress values calculated using the proposed formula (13).

We see that with uniaxial central reinforcement, the smallest discrepancy with the experimental data is obtained from formula (13).

\section{References}

1. Mikhailov V.V., Litver S.L. Expanding and stressing cements and self-stressed reinforced concrete structures. M., Stroyizdat,.-p 312. (1974)

2. Mikhailov V.V. and Litver S.L. Stressing cement technology and self-stressed structures. M., Stroyizdat, p.-184. (1975)

3. Mikhailov V.V. The use of concretes on stress cement in monolithic and precastmonolithic construction (review). M., (1975).

4. Instruction for the design of self-stressed reinforced concrete structures. CH 511-78. M., Stroyizdat, p 59. (1979)

5. Aroni S., Bertero U.V. and Polivka M. Chemically Prestressed Concrete, Journal «Prestressed Concrete Institute», 5, Okt., pp.22-25. (1968).

6. Aroni S. and Polivka M. Effekt of Expanded Shale Agregate on properties of Expansive Cement Concrete Proceeding RILEM. Simpozium o Zighweight Agregate Concretes, Budapest, March, pp. 475-502. (1967)

7. Salikhanov S. S., Livshits Ya. D., Shtilman E. I. Bridge roadway and the method of its construction. Author's certificate No. 804755. Bulletin of inventions, (6). (1981).

8. Saidkhan Salikhanov. Methodology for Calculating a Slab of a Bridge Web of Reinforced Tensile Concrete with Free Boundary Conditions. International Journal of Innovative Technology and Exploring Engineering (IJITEE) ISSN: 2278-3075, 2, (9), pp. 800-802, December 2019 (SCOPUS). (2019).

9. S.S.Salixanov. New Type of Road Bridge Riding Cloth Construction Using SelfTensioning Concrete. International Journal of Advanced Research in Science, Engineering and Technology. 6, (11). pp. 11655-11657, November 2019.

10. Ulugbek Shermuxamedov, Saidkhan Salikhanov, Said Shaumarov, Faxriddin Zokirov. Method of selecting optimal parameters of seismic-proof bearing parts of bridges and overpasses on high-speed railway lines. Journal of critical reviews. 2394-5125. 11, (7), pp. 1578-1585, (SCOPUS2020).

11. Wang, B. Distributed models of self-stress value in textile-reinforced self-stressing concrete, B. Wang, J. Zhao, Q. Wang. - Construction and Building Materials Journal. (126), pp 286 - 296. (2016) 
12. Tanimura, M. Serviceability performance evaluation of $R C$ flexural members improved by using low-shrinkage high-strength concrete, M. Tanimura, R. Sato, Y. Hiramatsu. - Journal of Advanced Concrete Technology. 2 (5), - pp. 149 - 160. (2007).

13. Ito, H. Early age deformation and resultant induced stress in expansive high strength concrete, H. Ito, I. Maruyama, M. Tanimura, R. Sato. - Journal of Advanced Concrete Technology. 2 (2), pp. 155 -174. (2011).

14. Kai-Cheng, X, Confined expansion and bond property of micro-expansive concretefilled steel tube columns, X. Kai-Cheng, C. Meng-Cheng, Y. Fang. - The Open Civil Engineering Journal. (5),. pp. 173 - 178. (2011).

15. Ishikawa, Y. Theoretical development of CP method in predicting expansive cement concrete cracking, Fracture Mechanics of Concrete and Concrete Structures / Y. Ishikawa, T. Tanabe. - Recent Advances in Fracture Mechanics of Concrete,. pp 398 405. (2010).

16. Semianiuk, V, Early age strains and self-stresses of expansive concrete members under uniaxial restraint conditions, Semianiuk V., Tur V., Herrador M.F., Paredes M. - Construction and Building Materials Journal. 1 (131), pp. 39 - 49. (2016).

17. CNR-DT 203/2006. Guide for the Design and Construction of Concrete Structures Reinforced with Fiber-Reinforced Polymer Bars. - National Research Council. Advisory Committee on Technical Recommendations for Construction. - Rome, June. p 35 c. (2007)

18. Titova L A Beilina M I and Titov M Yu, Expanding additives to increase the durability of the structure Inst.and Spec. Wor. in Constr. (2004).

19. Gridchina A A and Titova L A, Prospects for the use of concrete on the basis of expanding additives in modern monolithic construction Theor. and ap. asp. of mod. scien. 3 (2014).

20. Nesvetaev G V, Koryanova Yu I, The influence of the conditions of hardening of concrete with a two-stage extension on the deformative-strength indicators Nauk. (5). (2015).

21. Kuznetsova T V and Krivoborodov $\mathrm{Yu}$ R, The composition of the properties and the use of special cements Concr. Techn. 2 8-11 (2014) 